\title{
Inner Membrane Protein YhcB Interacts with RodZ Involved in Cell Shape Maintenance in Escherichia coli
}

\author{
Gaochi Li, Kentaro Hamamoto, and Madoka Kitakawa \\ Department of Biology, Faculty of Science, Kobe University, Rokko, Kobe, Hyogo 657-8501, Japan \\ Correspondence should be addressed to Madoka Kitakawa, madoka@kobe-u.ac.jp
}

Received 29 June 2012; Accepted 22 July 2012

Academic Editors: H. Lim and A. Maucuer

Copyright () 2012 Gaochi Li et al. This is an open access article distributed under the Creative Commons Attribution License, which permits unrestricted use, distribution, and reproduction in any medium, provided the original work is properly cited.

Depletion of $Y h c B$, an inner membrane protein of Escherichia coli, inhibited the growth of rodZ deletion mutant showing that the loss of both YhcB and RodZ is synthetically lethal. Furthermore, YhcB was demonstrated to interact with RodZ as well as several other proteins involved in cell shape maintenance and an inner membrane protein YciS of unknown function, using bacterial twohybrid system. These observations seem to indicate that YhcB is involved in the biogenesis of cell envelope and the maintenance of cell shape together with RodZ.

\section{Introduction}

Genome analyses predicted that a large number of genes encode cell membrane proteins. However, the majority of them have not well been investigated and remain as function unknown even in E. coli [1]. Various genome-wide approaches have recently been taken to examine and obtain clues for defining their function [2-7].

Protein YhcB has been localized to the inner membrane of E. coli and is suggested to be a subunit of cytochrome $b d$ type ubiquinol oxidase from proteome studies [8]. However, an investigation by Mogi et al. [9] could not confirm the association of $\mathrm{YhcB}$ with this oxidase and its role on assembly and function of the complex is elusive. It was reported that a deletion mutant of $y h c B$ could not grow at a critically high temperature [10], but no other phenotype of $y h c B$ deletion mutant was found and its cellular function has remained totally unknown. Previously we reported $y h c B$ as one of the function-unknown genes that reduce the biofilm formation upon its deletion [11]. In addition, the mutation appeared to cause a synthetically lethal phenotype with the deletion mutation of $\operatorname{rod} Z$, indicating a functional relationship between $y h c B$ and $\operatorname{rod} Z$. A deletion mutant of $\operatorname{rod} Z$ also exhibited reduced biofilm formation. $\operatorname{Rod} Z$ is an inner membrane protein and recently it was found to be required for rod-type cell determination [12-14]. Mutants of rodZ are nonmotile [11] and show a spherical phenotype similar to mutants of cell shape genes, $\operatorname{mrdAB}$ and $\operatorname{mreBCD}[15,16]$. However, $\operatorname{rod} Z$ is not an essential gene and after deletion a cell can divide and continue to grow unlike those of the latter genes. MrdA (PBP2) is an enzyme, elongation-specific transpeptidase, probably working in cooperation with PBP1A [17], while MreB is a bacterial actin homolog that forms helical structures underneath the cytoplasmic membrane. Others are inner membrane proteins and might form the elongase complex, a peptidoglycan (PG) synthesizing machine that elongates the PG side wall [18]. However the mechanism by which they participate in the elongation of PG and whether any other protein is required for the function of this complex is not known. In this study, we further investigated the interaction between $y h c B$ and $\operatorname{rod} Z$ by analyzing the synthetic phenotype and using a bacterial twohybrid system (BACTH) [19].

\section{Materials and Methods}

2.1. General Methods. Bacteria were routinely grown in LB media $(0.5 \% \mathrm{NaCl})$ at $37^{\circ} \mathrm{C}$. Antibiotics ampicillin $(100 \mu \mathrm{g} /$ $\mathrm{mL})$ and kanamycin $(40 \mu \mathrm{g} / \mathrm{mL})$ were added when required. Standard protocols for molecular cloning, transformation, and DNA/protein analyses were used [20]. Plasmids were constructed and purified using strain XL-1blue or DH5 $\alpha$. 
PCR was performed using PrimeStar (Takara Bio Inc. Japan) and genomic DNA of strain KR0401 or relevant plasmid DNA as template following the procedure recommended by enzyme supplier.

2.2. E. coli Strains and Plasmids. E. coli K12 strains and plasmids used in this work are listed in Table 1 together with primers used in PCR amplification. The integration of the inducible $y h c B$ gene into chromosome near att $\lambda, \lambda$ ( $a r a C$, $P_{\text {araBAD- }} y$ hcB, bla), was performed using $\lambda \mathrm{InCh}$ as previously described $[14,21]$.

In order to analyze the interaction of fusion proteins in the absence of RodZ or YhcB, $\Delta \operatorname{rodZ}:: k a n$ or $\Delta y h c B:: k a n$ mutations were introduced into JE8471 from corresponding Keio collection mutants [23] by P1 mediated transduction, then kanamycin resistance gene was eliminated through FLP recombination mediated by pCP20 [24]. Plasmid pKnT25 was constructed from pKTop [22] by replacing the region containing $p h o A$ and lac $Z$ fragment of the vector with the fragment coding for T25 using In-Fusion system (ClonTech/ Takara Bio). The T25 fragment was amplified by PCR using pKT25 as template and primers, pKTop-T25-5 (GATCCCCGGGTACCGAGCTCGAATTCAATGACCATGCAGCAATCGC) and pKTop-T25-3-rv (AGATTGTACTGAGAGTGCACTTATATCGATGGTGCAGCCCGCCGCGTGCG).

2.3. BACTH Analysis. Indicator strain JE8471 harboring indicated plasmids were grown in LB medium containing antibiotics and IPTG $(0.5 \mathrm{mM})$ at $30^{\circ} \mathrm{C}$. Cells were collected at a density of about $0.5 \mathrm{OD}_{600}$ and kept frozen at $-20^{\circ} \mathrm{C}$. Activity of $\beta$-galactosidase was measured according to Miller [25] except that cells were lysed by adding $0.2 \% \mathrm{~N}$-lauroylsarcosine (sodium salt) into Z-buffer [26]. Average and standard deviation were calculated from three independent measurements.

2.4. Electron Microscopy. Cells were stained by $1 \%$ uranyl acetate and observed by TEM as described previously [14].

\section{Results and Discussion}

3.1. YhcB Is Required for the Growth of $\Delta$ rodZ Mutants. In our previous investigation we found that the deletion of both $y h c B$ and $\operatorname{rod} Z$ genes caused synthetic lethality because we were unable to introduce the $y h c B:: k a n$ mutation into a $\Delta$ rodZ strain by P1 transduction [11]. We further examined this phenotype by constructing strains which harbor the $\Delta r o d Z \Delta y h c B$ double deletion mutation and an inducible $y h c B$ gene either on a plasmid or integrated in the chromosome, and monitoring the cell growth under $y h c B$-induced or repressed conditions. As shown in Figure 1(a), the growth of strain KR0413 ( $\triangle y h c B \quad \Delta$ rodZ::kan $\left.P_{a r a B A D^{-}} y h c B\right)$ was retarded when the cell density was about $\mathrm{OD}_{600}$ of 0.7 after 4.2 generations in a medium containing $0.2 \%$ glucose, whereas it continued beyond $\mathrm{OD}_{600}$ of 1.1 in the presence of $0.1 \% \mathrm{~L}$-arabinose. The growth inhibition in the presence of glucose was also observed on agar plates (Figure 1(b)). In the case of strain KR0411 that carried $P_{a r a B A D}-y h c B$ gene on a multicopy plasmid, cells continued to grow more than 5 generations under the repressed condition and the cell density reached over $1.1 \mathrm{OD}_{600}$. This might indicate that KR0411 probably contained more YhcB molecules than KR0413 and it took more generations under the repressing condition until the amount of $\mathrm{YhcB}$ in cell dropped to a critical level for the cell growth. On agar plates, this strain as well as KR0423 ( $\Delta$ rodZ $\left.\Delta y h c B:: k a n P_{a r a B A D}-y h c B\right)$ showed similar growth on L-arabinose and glucose medium (Figure 1(b), lane 4 and 5). The reason for this discrepancy is not clear but we assume that the effect of $\Delta \operatorname{rod} Z$ mutation on the cell is larger in liquid culture than on solid agar plates, probably because rodZ is important for PG synthesis [14] and cells with a defect in PG might not well resist the turgor pressure in a liquid environment. We often observed $\Delta \operatorname{rod} Z$ mutants lyse when cultured in liquid medium for a long period. KR0412 ( $\left.\triangle y h c B P_{a r a B A D^{-}} y h c B\right)$ and KR0422 ( $\Delta \operatorname{rodZ}$ $P_{a r a B A D}-y h c B$ ) as well as wild type cells (data not shown) grew similarly in the medium containing L-arabinose and glucose, which clearly showed that single mutation, either $\Delta y h c B$ or $\Delta \operatorname{rod} Z$, does not affect the growth in these conditions.

We previously reported [14] that $\Delta \operatorname{rodZ}$ mutants which are nonmotile often changed phenotype probably by acquiring a mutation(s) spontaneously. During the construction of double deletion strain starting from a $\Delta$ rodZ mutant a similar process seemed to have happened. The resultant strain KR0423 ( $\left.\Delta \operatorname{rodZ} \Delta y h c B:: k a n P_{a r a B A D}-y h c B\right)$ was found to be motile and grow much faster than KR0413 (Figure 1(a)). Interestingly, the growth of this strain seemed to be still dependent on the expression of the $y h c B$ gene, though the growth continued more than 5 generations and the cell density reached to $1.2 \mathrm{OD}_{600}$, about two fold of KR0413 in the repressing condition. Furthermore, the cell shape of KR0423 was found to be rod-type rather than spherical as KR0401 $\Delta$ rodZ-mot ${ }^{+}$, a previously reported motile derivative of KR0401 $\Delta$ rodZ mutant, and however KR0423 showed again a spherical phenotype when it was grown in the medium containing glucose and $\mathrm{YhcB}$ depleted (Figure 1(c)). This seems to further indicate that YhcB also participates in lateral cell growth by interacting with RodZ and probably with other components involved in cell morphogenesis.

3.2. YhcB Interacts with RodZ. Because the synthetic phenotype described above indicated a functional interaction between $\mathrm{YhcB}$ and RodZ, we investigated whether they associated in vivo using a BACTH system [19]. In this system, two complementary fragments T18 and T25 derived from the adenylate cyclase of Bordetella pertussis are fused with proteins of interest, expressed in a cyaA (adenylate cyclase) mutant strain and the activity of lac $Z$ is examined. In $E$. coli, cyclic AMP bound to the transcriptional activator, CAP, triggers transcriptional activation of catabolic operons, such as lactose. Therefore, in $\triangle c y a A$ strain (JE8471) the synthesis of cyclic AMP by the reconstructed adenylate cyclase of B. pertussis is required for the expression of lacZ. We first constructed YhcB-T18 and T25-RodZ fusions using plasmid pUT18 and pKT25, respectively, because it was predicted 
TABLE 1: E. coli strains and plasmids used in this study.

\begin{tabular}{|c|c|c|}
\hline Strain & Genotype $^{\mathrm{a}}$ & Source or reference \\
\hline XL-1Blue & $\begin{array}{l}\mathrm{F}^{\prime}\left[\text { proAB } B^{+} \text {, lacIq, lacZDM15::Tn10 (tetr)], hsdR17, }\right. \\
\text { supE44, recA1, endA1, gyrA46, thi, relA1, lac }\end{array}$ & Laboratory stock \\
\hline $\mathrm{DH} 5 \alpha$ & $\begin{array}{l}\left.\mathrm{F}^{-}, \text {deoR, endA1, gyrA96, hsdR17( } r k^{-} m k^{+}\right), \text {recA1, } \\
\text { relA1, supE44, thi-1, D (lacZYA-argF)U169, (f 80lacZ D M15) }\end{array}$ & Laboratory stock \\
\hline JE8471 & $D E($ cya)854, trp, his, ilv & $\begin{array}{l}\text { National } \\
\text { BioResource } \\
\text { Project }\end{array}$ \\
\hline BW25113 & $\begin{array}{l}\mathrm{F}^{-}, r p h-1, D E(r h a B A D) 568, D E(\operatorname{araBAD}) 567 \\
\text { DElacZ4787, hsdR514, rrnB }\end{array}$ & CGSC \\
\hline KR0401 & a derivaative of BW25113 & {$[11]$} \\
\hline KR0411 & KR0401 $\Delta y h c B /$ pBADs- $y h c B$ & This study \\
\hline KR0412 & KR0401 $\Delta y h c B, \lambda\left(a r a C, p_{a r a B A D}-y h c B, b l a\right)$ & This study \\
\hline KR0413 & KR0412 $\Delta$ rodZ::kan & This study \\
\hline KR0422 & KR0401 $\Delta \operatorname{rod} Z, \lambda\left(a r a C, p_{a r a B A D}-y h c B, b l a\right)$ & This study \\
\hline KR0423 & KR0422 $\Delta y h c B:: k a n$ & This study \\
\hline plasmid & Relevant features or primers used to amplify the indicated gene & \\
\hline pKT25 & BACTH vector, $\mathrm{Km}^{\mathrm{R}}$ & {$[22]$} \\
\hline pKnT25 & constructed from $\mathrm{pKTop}, \mathrm{Km}^{\mathrm{R}}$ & This study, [22] \\
\hline pUT18 & BACTH vector, $A p^{R}$ & {$[22]$} \\
\hline pUT18c & BACTH vector, $\mathrm{Ap}^{\mathrm{R}}$ & {$[22]$} \\
\hline pKnT25-rodA & $\begin{array}{l}\text { ctctagaGACGGATAATCCGAATAAAAAAA/ } \\
\text { gcggtaccACGCTTTTCGACAACATTTTCC }\end{array}$ & This study \\
\hline $\mathrm{pKnT} 25-y h c B$ & $y h c B$ derived from pUT18-yhcB & This study \\
\hline $\mathrm{pKT} 25-c y b D$ & $\begin{array}{l}\text { gctctagaGATCGATTATGAAGTATTGCGT/ } \\
\text { gcggatccTACAGAGAGTGGGTGTTACGTT }\end{array}$ & This study \\
\hline pKT25-mreB & $\begin{array}{l}\text { gctctagaGTTGAAAAAATTTCGTGGCATG/ } \\
\text { cgggatccTCTTCGCTGAACAGGTCGCCG }\end{array}$ & This study \\
\hline pKT25-mreC & $\begin{array}{l}\text { gctctagaGAAGCCAATTTTTAGCCGTGG/ } \\
\text { gcggtaccTGCCCTCCCGGCGCACGC }\end{array}$ & This study \\
\hline pKT25-mreD & $\begin{array}{l}\text { gctctagaGGCGAGCTATCGTAGCCAGGGA/ } \\
\text { gcggtaccTGCACTGCAAACTGCTGACGGA }\end{array}$ & This study \\
\hline pKT25-murG & $\begin{array}{l}\text { gctctagaGAGTGGTCAAGGAAAGCGATTA/ } \\
\text { gcggtaccGCCCGGGCAACCCGGCTCACTT }\end{array}$ & This study \\
\hline pKT25-rodZ & $\operatorname{rod} Z$ derived from $\mathrm{pUT} 18 \mathrm{c}-\operatorname{rod} Z$ & This study \\
\hline pKT25-yciS & $\begin{array}{l}\text { gctctagaGAAATATTTACTCATTTTCTTACTGGT/ } \\
\text { gcgaattcTTATTCCTTCGCCGCTGAC }\end{array}$ & This study \\
\hline pUT18c-rodZ & $\begin{array}{l}\text { gctctagaGAATACTGAAGCCACGCAC/ } \\
\text { ggaattCTGCGCCGGTGATTGTT }\end{array}$ & This study \\
\hline pUT18-ftsB & $\begin{array}{l}\text { gcctgcag GGGTAAACTAACGCTGCTGTTG/ } \\
\text { cgggatcc CGATTGTTTTGCCCCGCAGA }\end{array}$ & This study \\
\hline pUT18-yhcB & $\begin{array}{l}\text { gcctgcag GACCTGGGAATATGCGCTAATT/ } \\
\text { cgggatcc TCGCGCTTCGCGCCAGTA }\end{array}$ & This study \\
\hline pUT18- $y h c B \Delta C 1$ & $\begin{array}{l}\text { gcctgcagGACCTGGGAATATGCGCTAATT/ } \\
\text { cgggatccAGGCTGCTGGAGCTTTTTGC }\end{array}$ & This study \\
\hline pUT18- $y h c B \Delta C 2$ & $\begin{array}{l}\text { gcctgcagGACCTGGGAATATGCGCTAATT/ } \\
\text { cgggatccATCTGCACCGGTGCCTGATCGT }\end{array}$ & This study \\
\hline pUT18- $y h c B \Delta N$ & $\begin{array}{l}\text { gctctagaGCGTTTTGGTAATCGTAAACTAC/ } \\
\text { cgggatccTCGCGCTTCGCGCCAGTA }\end{array}$ & This study \\
\hline
\end{tabular}

\footnotetext{
${ }^{a} \lambda(\operatorname{araC}$ ParaBAD-yhcB) denotes chromosome integration mediated by $\lambda \mathrm{InCh}$.
} 


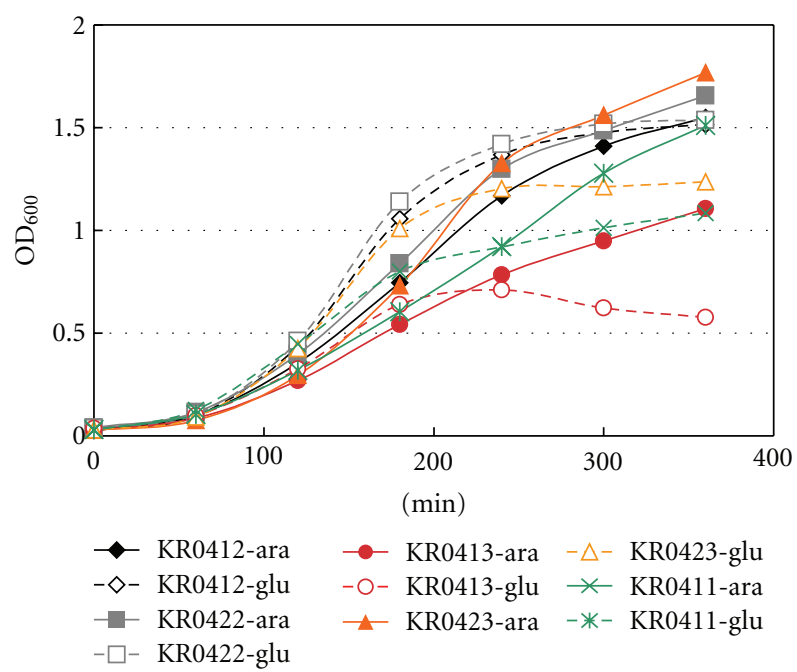

(a)

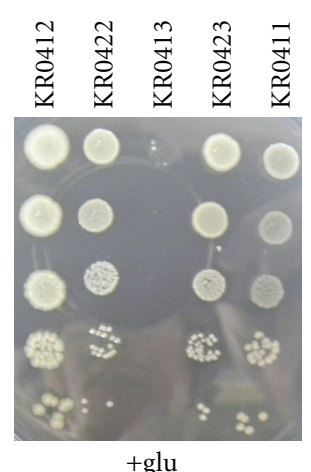

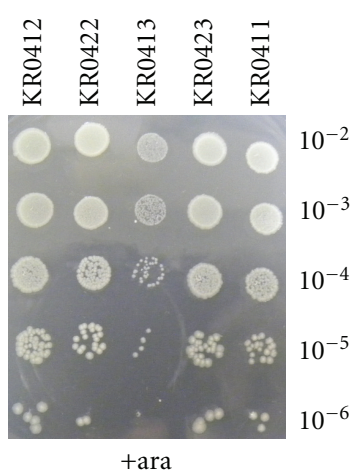

(b)
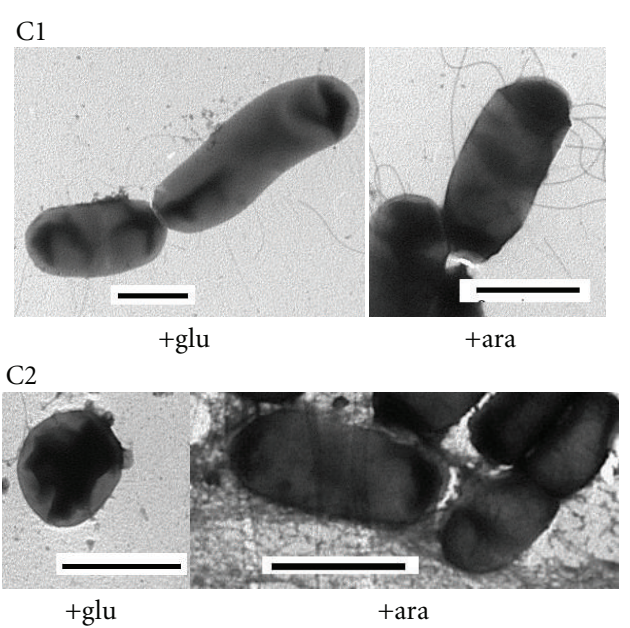

(c)

FIGURE 1: Growth of $\Delta y h c B \Delta \operatorname{rodZ}$ mutants carrying an inducible $y h c B$ gene. (a) Cells of indicated strains grown overnight in LB medium containing $0.1 \%$ arabinose were inoculated to give an $\mathrm{OD}_{600}$ of 0.025 into $\mathrm{LB}$ medium containing either $0.1 \%$ arabinose or $0.2 \%$ glucose. Ampicillin was also added at $100 \mu \mathrm{g} / \mathrm{mL}$ to the culture of strain KR0411. Aliquots of culture were taken and $\mathrm{OD}_{600} \mathrm{were}_{\mathrm{measured}}$ at indicated time intervals. KR0412 ( $\triangle y h c B \lambda\left(\operatorname{araC}, p_{a r a B A D}-y h c B, b l a\right)$ :diamond (black); KR0422 ( $\Delta \operatorname{rodZ} \lambda\left(\operatorname{araC}, p_{\operatorname{ara} a A D}-y h c B, b l a\right): s q u a r e$ (gray); KR0413 ( $\triangle y h c B \Delta \operatorname{rodZ::kan~} \lambda$ (araC, paraBAD-yhcB, bla):circle (red); KR0423 ( $\Delta$ rodZ $\Delta y h c B:: k a n \lambda($ araC, paraBAD-yhcB, bla):triangle (orange); KR0411 $(\Delta y h c B \Delta \operatorname{rodZ}:: k a n / p B A D s-y h c B)$ :cross (green). Solid $(-)$ and dotted $(\cdots)$ lines indicate the culture with arabinose and glucose, respectively. (b) Strains KR0412 ( $\Delta y h c B \lambda\left(\operatorname{araC}, p_{a r a B A D}-y h c B, b l a\right)$ ), KR0422 ( $\left.\operatorname{rodZ} \lambda\left(\operatorname{araC}, p_{a r a B A D}-y h c B, b l a\right)\right), \mathrm{KR} 0413(\Delta y h c B$

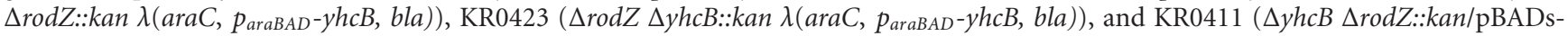
$y h c B$ ) were cultured in LB medium containing $0.1 \%$ arabinose. Tenfold serial dilutions were made and $5 \mu \mathrm{L}$ of each were spotted on LB agar plate containing either $0.1 \%$ arabinose or $0.2 \%$ glucose as indicated, and plates were incubated overnight at $37^{\circ} \mathrm{C}$. (c) Cell shape of $\mathrm{KR} 0423$ was observed by electron microscopy before (C1) and after (C2) the growth was retarded by YhcB depletion. Horizontal bar is $2 \mu \mathrm{m}$.

that both proteins have a single transmembrane domain and C-terminus of YhcB and N-terminus of RodZ are located in the cytoplasm [1]. The result on the indicator plate showed that indeed YhcB physically interacted with RodZ. Next, we investigated which part of YhcB is required for the interaction using deletion mutants of $y h c B$. As shown in Figure 2, YhcB $\Delta \mathrm{N}$ (amino acid residues 22-132) and YhcB $\Delta \mathrm{C} 1(1-84)$ did not show a detectable interaction but YhcB $\Delta \mathrm{C} 2$ (1-113) weekly interacted, indicating that the transmembrane domain (TM) and the cytoplasmic helical structures are required and the extreme C-terminal region predicted to have no secondary structure [27] is also important for interaction with RodZ. However, Western blot analysis of fusion proteins in cells harboring plasmids exhibited that protein amounts of deletion mutants are significantly reduced (data not shown), indicating that these truncated $\mathrm{YhcB}$ fusions were unstable and this could be the reason of observed low $\beta$-galactosidase activity. Alternatively, the absence of interaction might have led to the degradation of unincorporated proteins. In any event, the C-terminal 


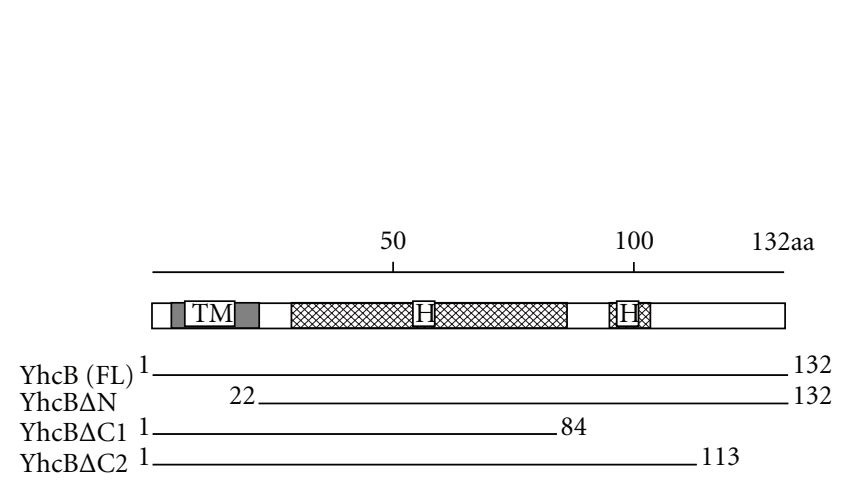

(a)

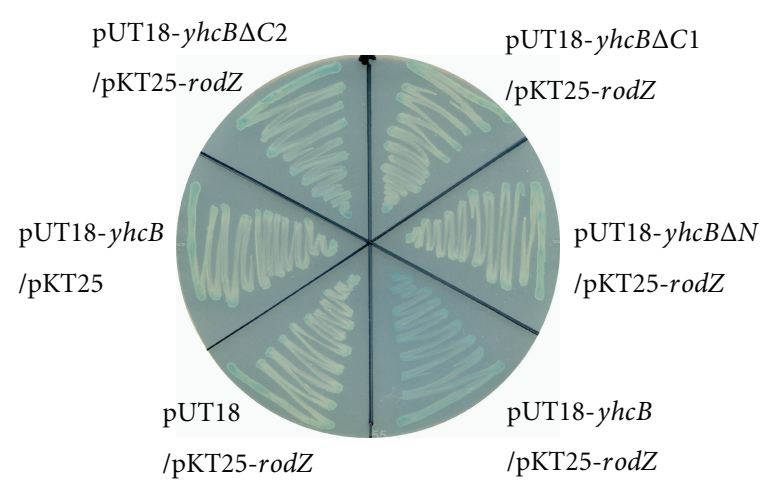

(b)

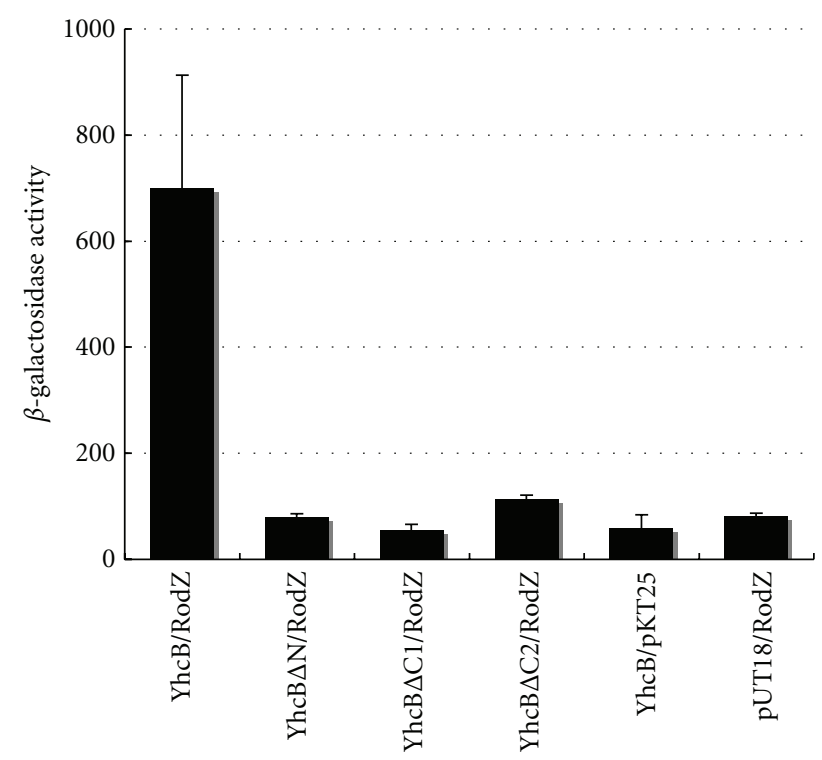

(c)

FIGURE 2: Interaction of YhcB and RodZ detected by BACTH system. (a) Schematic representation of YhcB and its truncated derivatives. Predicted transmembrane domain (TM) and cytoplasmic helical structures (H) are indicated. Thick lines with numbers of amino acid residues show regions cloned into indicated plasmids. (b) Indicated plasmids were cotransformed into JE8471 and resultant transformants were streaked on a LB indicator plate containing X-gal $(40 \mu \mathrm{g} / \mathrm{mL})$ and IPTG $(0.5 \mathrm{mM})$, and incubated at $30^{\circ} \mathrm{C}$ for one day. Blue colour indicates a positive interaction between each fusion protein. (c) Interaction in each cotransformants was also examined quantitatively by $\beta$-gal assay as described in Section 2.

region of YhcB seemed to be important for its interaction with RodZ. On the other hand, the helix-turn-helix domain (amino acid residues 30-49) of RodZ required for proper function of RodZ [14] was dispensable for the interaction (data not shown).

3.3. YhcB Interacts with Cell Shape Proteins. Because RodZ is important for rod-type cell determination and interacts with proteins involved in cell morphogenesis [13], we further examined whether YhcB also interacts with these proteins and MurG, an enzyme in the pathway of peptidoglycan synthesis. In order to perform BACTH analysis, mreB, mreC, $m r e D$, and murG were cloned into pKT25 and rodA into $\mathrm{pKnT} 25$, respectively, and $\beta$-galactosidase activities of transformants carrying one of these constructs and pUT18-yhcB were measured. The results obtained indicated that $\mathrm{YhcB}$ interacts with MreC, MreD, RodA, and MurG, but not with MreB (Table 2).

Here, it was notable that unlike RodZ that seems not to interact with MurG and other peptidoglycan synthesizing enzymes [13, 28], YhcB showed a significant interaction activity with MurG. On the other hand $\mathrm{YhcB}$ seems not to interact with cytoskeleton protein MreB. In addition, the interactions were studied in a $\triangle \operatorname{rod} Z$ derivative of indicator strain JE8471 to investigate whether the association of YhcB with these cell shape proteins is independent on the presence of RodZ. As shown in Figure 3, interactions with these cell shape proteins were also detected in the absence of RodZ (JE8471 $\Delta$ rodZ), though the interaction with MurG seemed to be weaker compared to the wild type strain. This might indicate that RodZ somehow participates in the interaction 
TABLE 2: BACTH analysis of interaction between YhcB and inner membrane proteins.

\begin{tabular}{lcc}
\hline & \multicolumn{2}{c}{$\beta$-gal activity $^{\mathrm{a}}$} \\
T25-plasmid $^{\mathrm{b}}$ & YhcB-T18 $^{-}$ & T18 \\
\hline T25-MurG & $269.6 \pm 60.7$ & $71.4 \pm 5.5\{\}\{\}\{\}$ \\
T25-MreB & $68.0 \pm 9.2$ & $73.7 \pm 9.2$ \\
T25-MreC & $476.6 \pm 3.0$ & $71.2 \pm 6.3$ \\
T25-MreD & $254.5 \pm 52.4$ & $75.6 \pm 22.5$ \\
RodA-T25 & $379.7 \pm 19.1$ & $82.7 \pm 18.6$ \\
T25-RodZ & $701.1 \pm 211.7$ & $80.6 \pm 6.1$ \\
T25-CydB & $87.3 \pm 27.8$ & $70.9 \pm 10.9$ \\
T25-YciS & $853.4 \pm 685.6$ & $78.2 \pm 2.1$ \\
T25 & $59.3 \pm 24.4$ & $31.1 \pm 21.6$ \\
\hline T18-plasmid & YhcB-T25 & T25 \\
\hline T18-RodZ & $294.5 \pm 14.2$ & $78.0 \pm 7.9$ \\
T18-FtsB & $82.7 \pm 6.3$ & $64.9 \pm 14.1$ \\
YhcB-T18 & $1236.8 \pm 398.2$ & $59.3 \pm 24.4$ \\
\hline
\end{tabular}

Interaction between $\mathrm{YhcB}$ and indicated proteins were quantified by measuring $\beta$-galactosidase activities of transformants harboring the corresponding plasmids.

${ }^{a}$ Numbers indicate averages of $\beta$-galactosidase activity (Miller's unit) with standard deviations. T18 and T25 show vector only.

bPlasmids with T25-CyaA domain appended to N (T25-) or C (-T25) terminus of indicated proteins.

${ }^{c}$ Plasmids with T18 CyaA domain appended to N (T18-) or C (-T18) terminus of indicated proteins.

between YhcB and MurG, for example, by stabilizing their association. However, the overproduction of RodA-T25 and T25-MurG fusion proteins in $\triangle \mathrm{rodZ}$ mutant could be deleterious to the cell, because about $60 \%$ of transformants were blue but the rests were nearly white, and a significant number of these could not grow upon single-colony purification. This could be the reason why the color of pKT25-murG transformants of JE8471 $\Delta$ rodZ was lighter than that of JE8471. In the white cells, T25-MurG fusion protein was probably not produced.

We also investigated whether YhcB interacts with $\mathrm{CydB}$, a component of cytochrome $b d$-I oxidase, and a cell division protein FtsB. No apparent interaction was observed between YhcB and $\mathrm{CydB}$, which further supported the conclusion by Mogi et al. [9] that YhcB is dispensable for the assembly and function of cytochrome $b d-1$ oxidase. FtsB, a divisome assembly protein [29], likewise showed no detectable activity with $\mathrm{YhcB}$, indicating that $\mathrm{YhcB}$ does not associate with divisome nor merely interact with proteins anchored in IM (inner membrane).

3.4. Possible Function of YhcB. Recent global analysis of interacting proteins [7] indicated that $\mathrm{YhcB}$ associated with YciS, an IM protein of unknown function. Therefore, we next examined this using BACTH system. YciS has two TM domains and both $\mathrm{N}$ - and $\mathrm{C}$-termini of the protein were predicted to be cytoplasmic [30]. Therefore, YciS was cloned into pKT25 and interaction with YhcB-T18 was examined. The result showed that they indeed interacted (Table 2). In addition, YciS was found to show a significant interaction

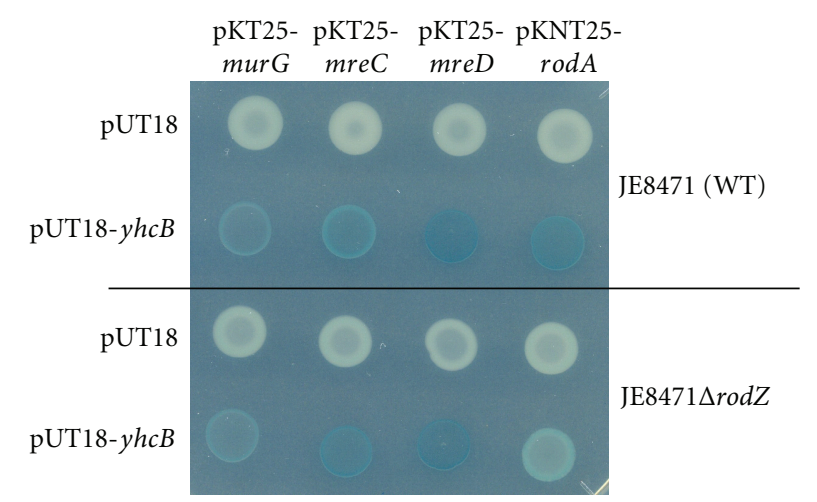

FIGURE 3: Interactions of $\mathrm{YhcB}$ and shape proteins are RodZ independent. Indicated plasmids and $\mathrm{pUT} 18-y h c B$ or $\mathrm{pUT} 18$ vector were cotransformed into JE8471 (upper) or JE8471 $\Delta \operatorname{rodZ}$ (lower) and interactions were examined as described in Figure 2(b).

with RodZ and this interaction was independent of $\mathrm{YhcB}$ because similar $\beta$-galactosidase activity was shown in $\Delta y h c B$ indicator strain (data not shown). Furthermore, YciS showed a significant interaction with FtsB (data not shown). Though further examination is necessary, intriguingly this might indicate that YciS participates both in lateral elongation of peptidoglycan and septum formation. Finally, it was predicted that YhcB forms a homooligomeric complex [31]. Our BACTH analysis supported this by detecting a strong selfinteraction (Table 2).

Taking together all interactions detected by BACTH, we speculate that the complex integrated in IM consisting of YhcB, RodZ, and YciS together with cell shape proteins MreCD and RodA assists PG synthesis by directing enzymes and other molecules required at the site of PG synthesis. Probably they primarily function in the cell elongation but might also participate in septum formation and therefore the more severe defect caused by the simultaneous loss of RodZ and YhcB inhibited the cell growth.

\section{Conclusion}

We showed the synthetic lethality of $y h c B$ and $\operatorname{rod} Z$ deletion mutations by constructing a strain that harbors double deletion mutations and carries an inducible $y h c B$ gene on the chromosome. Furthermore, using BACTH system, the YhcB protein was shown to interact with cell shape proteins RodZ, MreCD, and RodA, an enzyme required for PG synthesis, MurG, and a function-unknown YciS that also interacted with RodZ.

Because the loss of YhcB showed neither a growth defect nor apparent phenotype in general culture conditions, the function of YhcB has remained obscure. However, our investigations seemed to indicate the involvement of this protein in cell shape determination and/or the biosynthesis of peptidoglycan cooperating with RodZ. Recent extensive investigations identified a large number of proteins involved in the murein synthesis and cell morphogenesis [18, 32]. However, it is still not clear how these proteins are organized and function in IM, whether they participate also in the 
septum formation and what is the mechanism to regulate the cell elongation and cell division. Further investigation of $\mathrm{YhcB}$ and RodZ as well as of YciS would give more insights into the elaborated mechanisms of cell envelope biosynthesis and its regulation. These proteins could also be the targets of new antimicrobial drugs, because the biofilm formation is a critical factor in pathogenicity $[33,34]$ and the loss of these proteins caused reduced biofilm formations.

\section{Acknowledgments}

The authors would like to thank Dr. Daniel Ladant of Institute Pasteur for kindly providing them with plasmid pKTop. The authors are grateful to Dr. Eric Dabbs (University of the Witwatersrand, South Africa) for his critical reading of the paper.

\section{References}

[1] R. V. Misra, R. S. P. Horler, W. Reindl, I. I. Goryanin, and G. H. Thomas, "EchoBASE: An integrated post-genomic database for Escherichia coli," Nucleic Acids Research, vol. 33, pp. D329D333, 2005.

[2] H. Tao, C. Bausch, C. Richmond, F. R. Blattner, and T. Conway, "Functional genomics: expression analysis of Escherichia coli growing on minimal and rich media," Journal of Bacteriology, vol. 181, no. 20, pp. 6425-6440, 1999.

[3] H. Mori, K. Isono, T. Horiuchi, and T. Miki, "Functional genomics of Escherichia coli in Japan," Research in Microbiology, vol. 151, no. 2, pp. 121-128, 2000.

[4] G. Butland, J. M. Peregrin-Alvarez, J. Li et al., "Interaction network containing conserved and essential protein complexes in Escherichia coli," Nature, vol. 433, no. 7025, pp. 531-537, 2005.

[5] M. Arifuzzaman, M. Maeda, A. Itoh et al., "Large-scale identification of protein-protein interaction of Escherichia coli K12," Genome Research, vol. 16, no. 5, pp. 686-691, 2006.

[6] J. J. Faith, B. Hayete, J. T. Thaden et al., "Large-scale mapping and validation of Escherichia coli transcriptional regulation from a compendium of expression profiles," PLoS Biology, vol. 5, no. 1, p. e8, 2007.

[7] P. Hu, S. C. Janga, M. Babu et al., "Global functional atlas of Escherichia coli encompassing previously uncharacterized proteins," PLoS Biology, vol. 7, no. 4, p. e96, 2009.

[8] F. Stenberg, P. Chovanec, S. L. Maslen et al., "Protein complexes of the Escherichia coli cell envelope," Journal of Biological Chemistry, vol. 280, no. 41, pp. 34409-34419, 2005.

[9] T. Mogi, E. Mizuochi-Asai, S. Endou, S. Akimoto, and H. Nakamura, "Role of a putative third subunit YhcB on the assembly and function of cytochrome bd-type ubiquinol oxidase from Escherichia coli," Biochimica et Biophysica Acta, vol. 1757, no. 7, pp. 860-864, 2006.

[10] M. Murata, H. Fujimoto, K. Nishimura et al., "Molecular strategy for survival at a critical high temperature in eschierichia coli," PLoS ONE, vol. 6, no. 6, Article ID e20063, 2011.

[11] E. T. E. Niba, Y. Naka, M. Nagase, H. Mori, and M. Kitakawa, "A genome-wide approach to identify the genes involved in biofilm formation in E. coli," DNA Research, vol. 14, no. 6, pp. 237-246, 2007.

[12] D. Shiomi, M. Sakai, and H. Niki, "Determination of bacterial rod shape by a novel cytoskeletal membrane protein," The EMBO Journal, vol. 27, no. 23, pp. 3081-3091, 2008.

[13] F. O. Bendezú, C. A. Hale, T. G. Bernhardt, and P. A. J. De Boer, "RodZ (YfgA) is required for proper assembly of the
MreB actin cytoskeleton and cell shape in E. coli," The EMBO Journal, vol. 28, no. 3, pp. 193-204, 2009.

[14] E. T. E. Niba, G. Li, K. Aoki, and M. Kitakawa, "Characterization of rodZ mutants: RodZ is not absolutely required for the cell shape and motility," FEMS Microbiology Letters, vol. 309, no. 1, pp. 35-42, 2010.

[15] M. Wachi, M. Doi, S. Tamaki, W. Park, S. Nakajima-Iijima, and M. Matsuhashi, "Mutant isolation and molecular cloning of mre genes, which determine cell shape, sensitivity to mecillinam, and amount of penicillin-binding proteins in Escherichia coli," Journal of Bacteriology, vol. 169, no. 11, pp. 4935-4940, 1987.

[16] S. Tamaki, H. Matsuzawa, and M. Matsuhashi, "Cluster mrdA and $\mathrm{mrdB}$ genes responsible for the rod shape and mecillinam sensitivity of Escherichia coli," Journal of Bacteriology, vol. 141, no. 1, pp. 52-57, 1980.

[17] M. Banzhaf, B. van den Berg van Saparoea, M. Terrak et al., "Cooperativity of peptidoglycan synthases active in bacterial cell elongation," Molecular Microbiology, vol. 85, no. 1, pp. 179-194, 2012.

[18] W. Vollmer and U. Bertsche, "Murein (peptidoglycan) structure, architecture and biosynthesis in Escherichia coli," Biochimica et Biophysica Acta, vol. 1778, no. 9, pp. 1714-1734, 2008.

[19] G. Karimova, J. Pidoux, A. Ullmann, and D. Ladant, "A bacterial two-hybrid system based on a reconstituted signal transduction pathway," Proceedings of the National Academy of Sciences of the United States of America, vol. 95, no. 10, pp. 5752-5756, 1998.

[20] J. Sambrook and D. W. Russell, Molecular Cloning. A Laboratory Manual, Cold Spring Harbour Laboratory, Cold Spring Harbor, NY, USA, 2001.

[21] D. Boyd, D. S. Weiss, J. C. Chen, and J. Beckwith, "Towards single-copy gene expression systems making gene cloning physiologically relevant: lambda InCh, a simple Escherichia coli plasmid-chromosome shuttle system," Journal of Bacteriology, vol. 182, no. 3, pp. 842-847, 2000.

[22] G. Karimova, C. Robichon, and D. Ladant, "Characterization of YmgF, a 72-residue inner membrane protein that associates with the Escherichia coli cell division machinery," Journal of Bacteriology, vol. 91, no. 1, pp. 333-346, 2009.

[23] T. Baba, T. Ara, M. Hasegawa et al., "Construction of Escherichia coli K-12 in-frame, single-gene knockout mutants: the Keio collection," Molecular Systems Biology, vol. 2, Article ID msb4100050, p. 2006.0008, 2006.

[24] K. A. Datsenko and B. L. Wanner, "One-step inactivation of chromosomal genes in Escherichia coli K-12 using PCR products," Proceedings of the National Academy of Sciences of the United States of America, vol. 97, no. 12, pp. 6640-6645, 2000.

[25] J. H. Miller, Experiments in Molecular Genetics, Cold Spring Harbor laboratory, Cold Spring Harbor, NY, USA, 1972.

[26] F. Kippert, "A rapid permeabilization procedure for accurate quantitative determination of $\beta$-galactosidase activity in yeast cells," FEMS Microbiology Letters, vol. 128, no. 2, pp. 201-206, 1995.

[27] B. Rost, G. Yachdav, and J. Liu, "The PredictProtein server," Nucleic Acids Research, vol. 32, pp. W321-W326, 2004.

[28] C. L. White, A. Kitich, and J. W. Gober, "Positioning cell wall synthetic complexes by the bacterial morphogenetic proteins MreB and MreD," Molecular Microbiology, vol. 76, no. 3, pp. 616-633, 2010.

[29] M. D. Gonzalez and J. Beckwith, "Divisome under construction: distinct domains of the small membrane protein ftsb are 
necessary for interaction with multiple cell division proteins," Journal of Bacteriology, vol. 191, no. 8, pp. 2815-2825, 2009.

[30] A. A. Porollo, R. Adamczak, and J. Meller, "POLYVIEW: A flexible visualization tool for structural and functional annotations of proteins," Bioinformatics, vol. 20, no. 15, pp. 24602462, 2004.

[31] G. Maddalo, F. Stenberg-Bruzell, H. Götzke et al., "Systematic analysis of native membrane protein complexes in Escherichia coli," Journal of Proteome Research, vol. 10, no. 4, pp. 18481859, 2011.

[32] T. Den Blaauwen, M. A. De Pedro, M. Nguyen-Distèche, and J. A. Ayala, "Morphogenesis of rod-shaped sacculi," FEMS Microbiology Reviews, vol. 32, no. 2, pp. 321-344, 2008.

[33] P. Landini, D. Antoniani, J. G. Burgess, and R. Nijland, "Molecular mechanisms of compounds affecting bacterial biofilm formation and dispersal," Applied Microbiology and Biotechnology, vol. 86, no. 3, pp. 813-823, 2010.

[34] J. B. Kaplan, "Biofilm dispersal: mechanisms, clinical implications, and potential therapeutic uses," Journal of dental research, vol. 89, no. 3, pp. 205-218, 2010. 

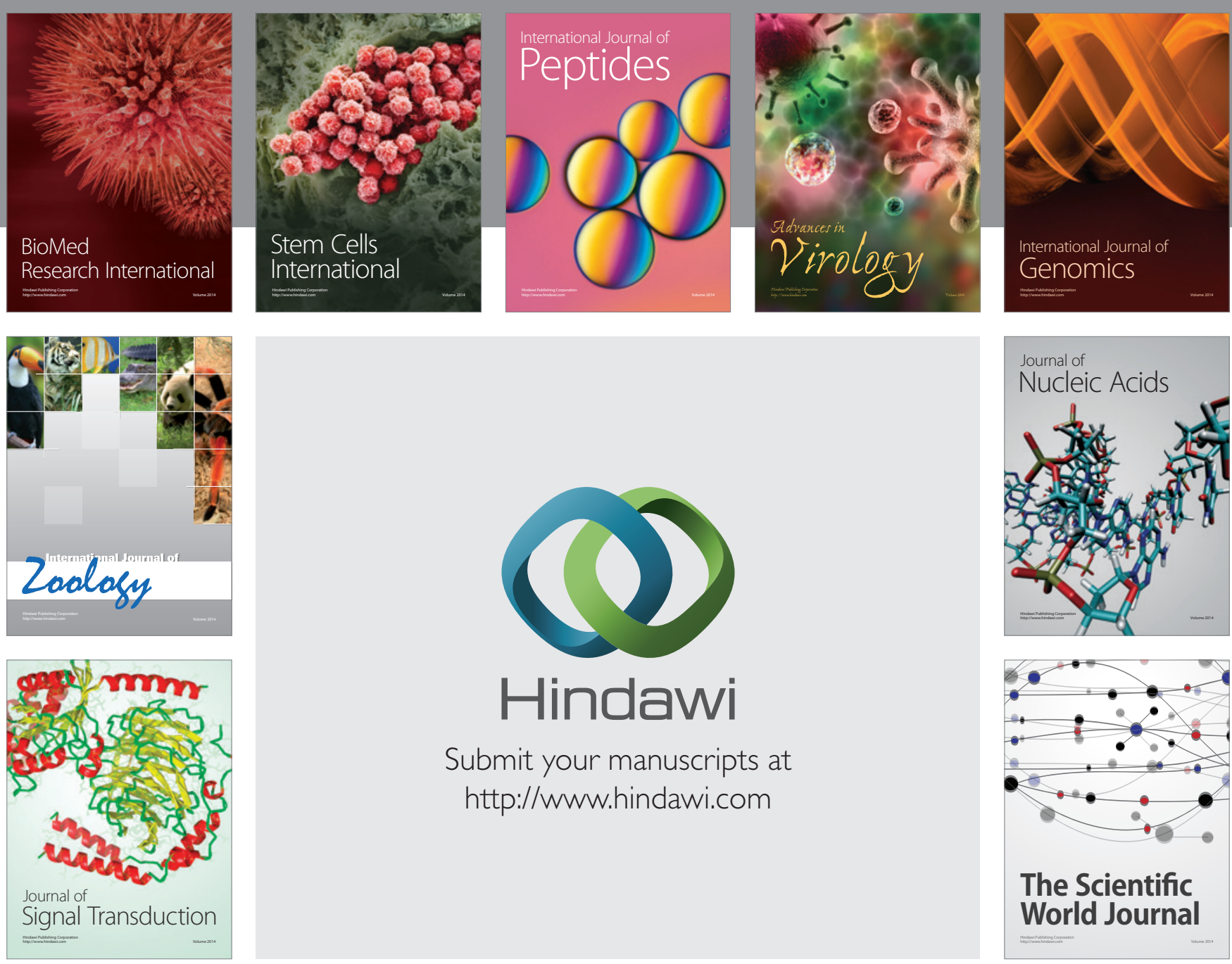

Submit your manuscripts at

http://www.hindawi.com
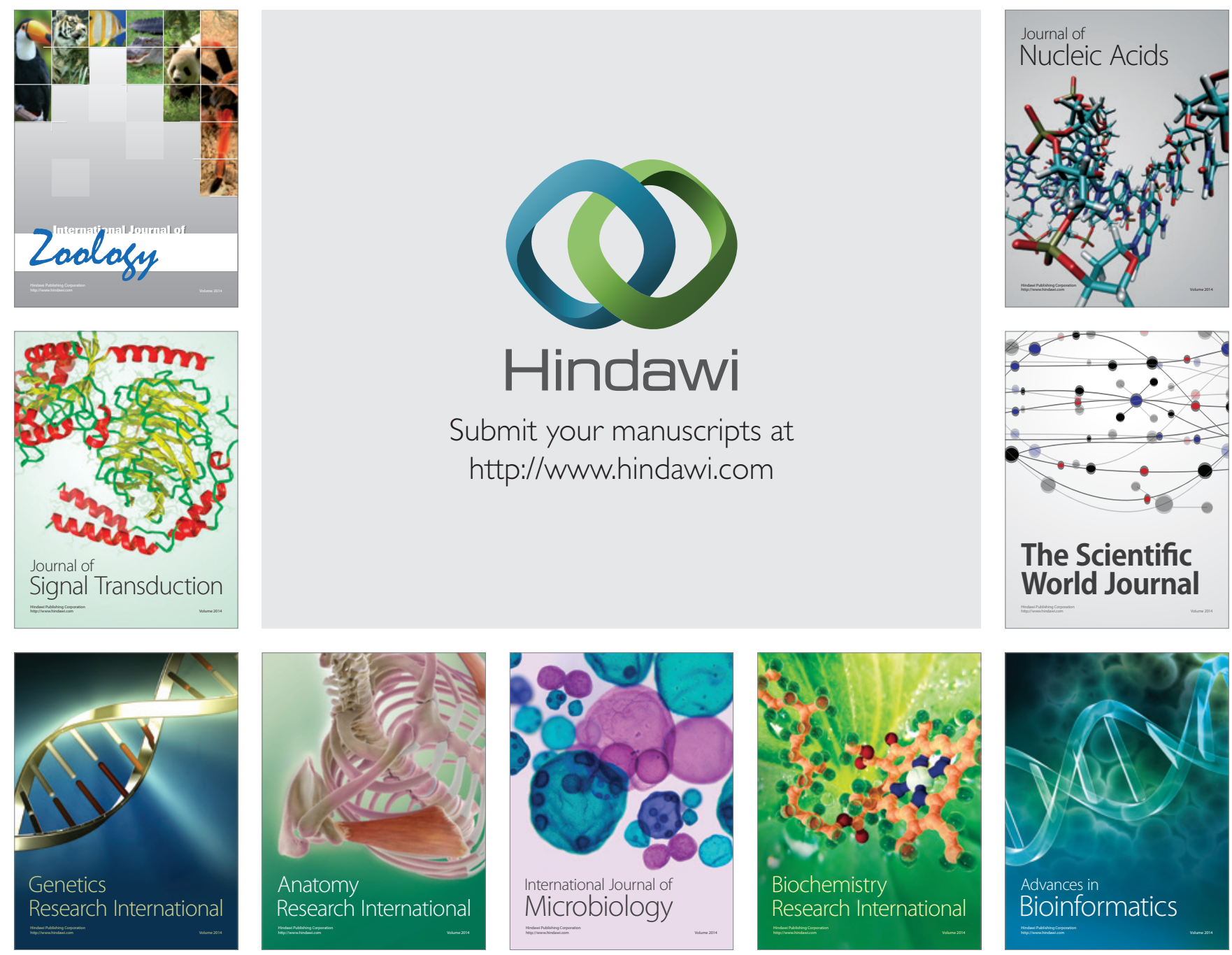

The Scientific World Journal
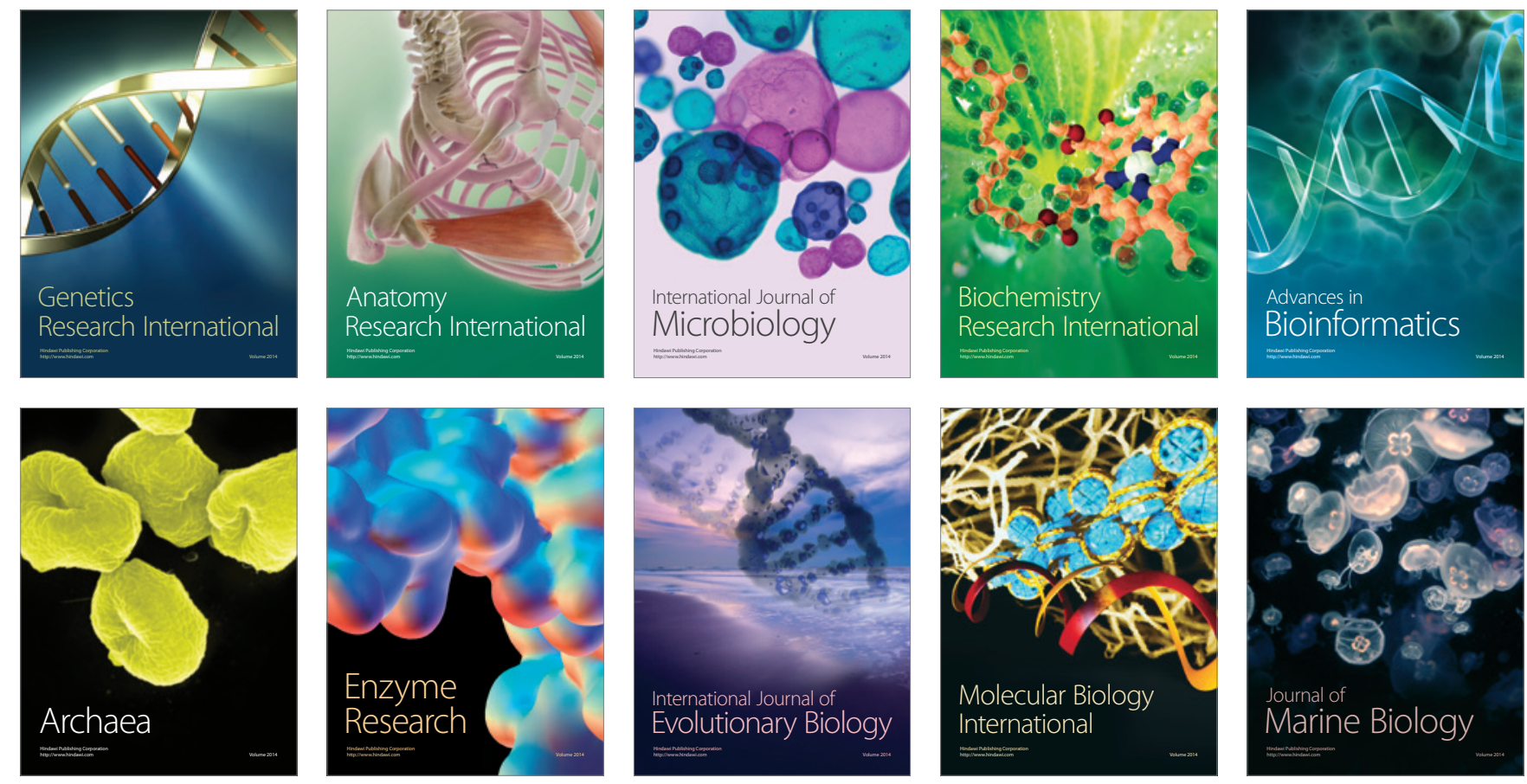